\title{
Optimal sizing of Marine Current Energy Based Hybrid Microgrid
}

\author{
N. Lazaar ${ }^{1,2}$, E. Fakhri ${ }^{1}$, M. Barakat ${ }^{1}$, H. Gualous ${ }^{1}$ and J. Sabor ${ }^{2}$ \\ ${ }^{1}$ Department of Electrical Engineering \\ LUSAC Laboratory, University of Caen Normandy, \\ 145 Chemin de la Crespinière, 50130 Cherbourg (France) \\ Phone: +33233 014204, e-mail: nouhaila.lazaar@unicaen.fr, eyman.fakhri@unicaen.fr, \\ mahmoud.barakat@unicaen.fr, hamid.gualous@unicaen.fr \\ ${ }^{2}$ ENSAM, LSMI Laboratory, University of Moulay Ismail, \\ Marjane 2, 50050 Meknes (Morocco) \\ e-mail: j.sabor@ensam.umi.ac.ma
}

\begin{abstract}
This paper presents an optimal sizing of a marine current energy-based hybrid microgrid. For this purpose, a particle swarm optimization (PSO) has been developed on Matlab software. An energy management strategy that takes into account the availability of renewable energy and energy consumption at all times has been implemented to meet demand throughout the year. In order to test the performance of the PSO, the results were compared to those obtained by the genetic algorithm (GA). The standard household load profile is selected to model an island residential loads variation. The Alderney Race (Raz-Blanchard in French) site is chosen as a case study for our marine energy system because its currents are among the highest in the world.
\end{abstract}

Keywords. Energy management strategy, marine current energy, microgrid, PSO.

\section{Introduction}

With the rapid increase in energy consumption worldwide, renewable energies, such as solar and tidal, are proving to be an effective solution to replace fossils fuels, which are non-renewable and environmentally unfriendly. However, their unpredictable behavior and dependence on weather conditions make their integration into microgrids very challenging. Therefore, hybrid systems present a better option to increase the reliability of the electricity supply.

The sizing of the system components is an essential step in designing a reliable and low-cost system with high penetration of renewables in the energy mix. Researchers have addressed this concern in several ways. HOMER has widely been used in different case studies [1]-[3]. Although it is a powerful tool facilitating the hybrid systems optimization with a minimum net present cost, "Black box" code utilization doesn't represent the source characteristics exactly [4]. Heuristic optimization algorithms, such as genetic algorithm (GA) and particle swarm optimization (PSO), have also been utilized, for grid-connected and isolated hybrid systems as well. The latter has become one of the favorite optimization methods due to its high-speed convergence for single-objective optimization. In [5], the authors have used PSO to determine the optimal sizing of a hybrid microgrid system intended to supply energy to households. They have considered the lowest cost of electricity (COE) and the loss of power supply probability (LPSP) as objective functions to design a reliable and highquality power supply with a competitive cost. Hakimi et al. [6] presented a sizing methodology for a wind-fuel cell hybrid system, using PSO. Hydrogen is produced from municipal waste and stored for later use in the case of an energy deficit. The results showed that the hybridization of the system has led to greater reliability and better energy management while optimizing the total cost. In [7], an MPSO ( modified PSO ) based optimal configurations and sizing of a hybrid PV/wind/battery system was presented. The authors have implemented the code in Matlab software, whose purpose is to ensure a balance between energy supply and demand sides while minimizing the total investment cost of the system. Results showed that the proposed approach leads to a faster convergence speed and a shorter computational time than the conventional PSO. In [8], the authors proposed a new methodology for the design of a multi-source system integrated with real time energy management (EMS) based on GA. Feroldi et al. have concluded that the bioethanol-fuel cell system allows reducing the other components sizing while ensuring its performance. In [9], pigeon inspired optimization has been applied to optimize a standalone hybrid PV/wind energy system considering the levelized cost of energy (LCE) as an objective function. The results proved that the $\mathrm{PV} /$ wind/battery system is more cost-effective than the wind/battery system and better meets the battery storage needs. Moreover, four well-known heuristic algorithms were applied by the authors of [10] for the hybrid water pumping system optimal sizing, namely; BAT algorithm (BA), cuckoo search algorithm (CS), firefly algorithm (FA) and flower pollination algorithm (FP). Life cycle cost (LCC) has been defined as an objective function. They have concluded that $\mathrm{CS}$ is more promising than the other 
algorithms in terms of the LCC. Other methods have been used to address this issue such as in [11]-[14].

In this paper, the optimal sizing of a standalone hybrid renewable energy system is introduced. For this purpose, particle swarm optimization (PSO) and genetic algorithm (GA) have been developed on MATLAB software, considering the loss of power supply probability (LPSP) and the equivalent loss factor (ELF) as reliability indices [5], [15].

Solar and tidal currents have been selected as the primary sources for feeding a residential island load, which is represented by the household profile as shown in Fig. 1. Although the place of solar energy remains minimal, it is now promised to grow vigorously worldwide [16]. Tidal energy has also gained popularity recently due to its high predictability [17]. The hydrogen system is chosen as the primary storage system to supply the load during fluctuations. The LiFePO4 battery is selected as a backup system to smooth the fast dynamics of the energy [18].

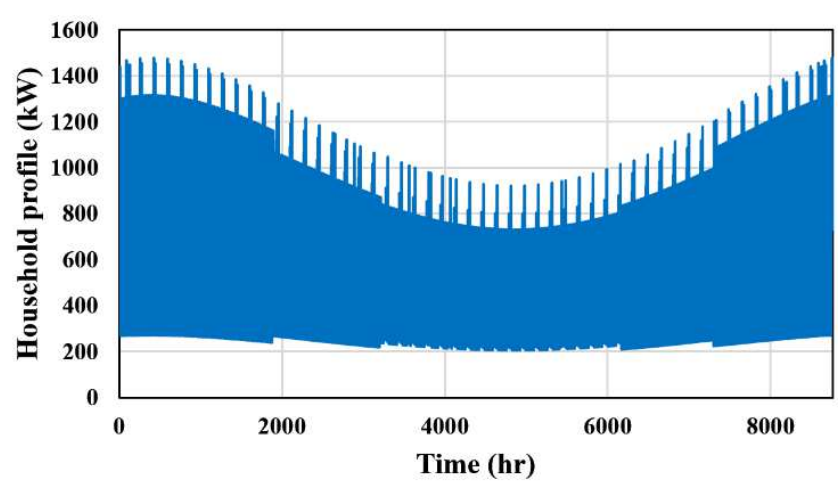

Fig. 1. Household annual load profile.

\section{System description}

As stated above, the hybrid system includes tidal turbines, PV panels, batteries, and hydrogen storage system. The latter is composed of an electrolyzer, a fuel cell, and a hydrogen tank. Fig. 2 illustrates the final architecture of our system.

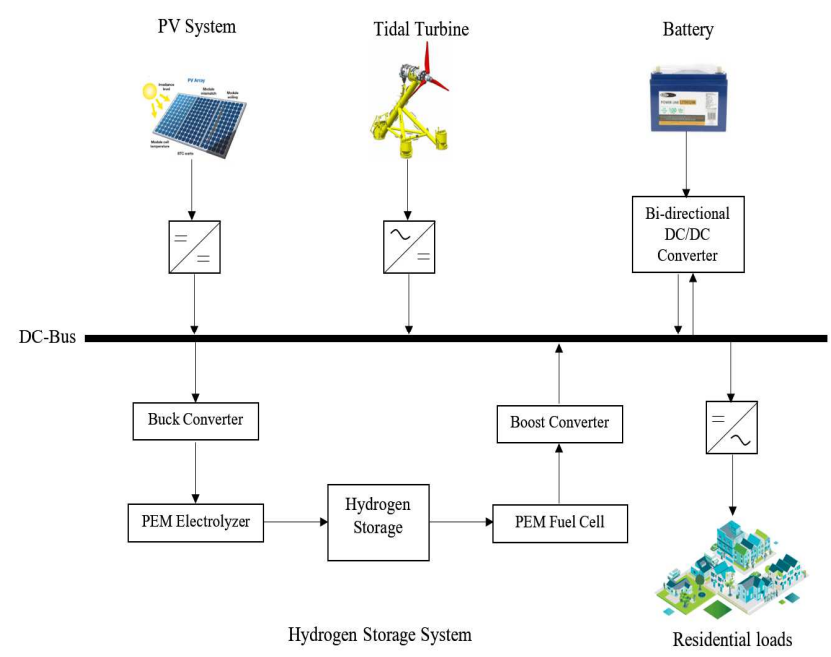

Fig. 2. Hybrid system architecture.

\section{A. Photovoltaic}

PV generator is a device that produces electricity from light [19]. The power generated from the PV panels is a function of solar radiation and temperature, it is given by (1) [20].

$$
P_{p v}=N_{p v} \cdot P_{r-p v} \cdot \frac{G}{G_{r e f}} \cdot\left[1+K_{t} \cdot\left(T_{c}-T_{r e f}\right)\right]
$$

Where $N_{p v}$ is the number of PV arrays, $P_{r-p v}$ is the rated power under standard test conditions $(\mathrm{kW}), G$ is the solar radiation $\left(\mathrm{W} / \mathrm{m}^{2}\right), G_{\text {ref }}$ is $1000 \mathrm{~W} / \mathrm{m}^{2}, K_{t}$ is $-3,7.10^{-3}, T_{\text {ref }}$ is $25{ }^{\circ} \mathrm{C}$ and $T_{c}$ is the cell temperature $\left({ }^{\circ} \mathrm{C}\right)$. The latter is a function of the ambient temperature $\left(T_{a}\right)$, the solar radiation $(G)$ and the nominal operating cell temperature (NOCT). Its value can be calculated by (2).

$$
T_{c}=T_{a}+G \cdot\left(\frac{N O C T-20}{800}\right)
$$

The annual solar radiation data from Cherbourg have been used in our study. For clarity, we present only daily data, as shown in Fig. 3. The photovoltaic array characteristics are presented in Table I.

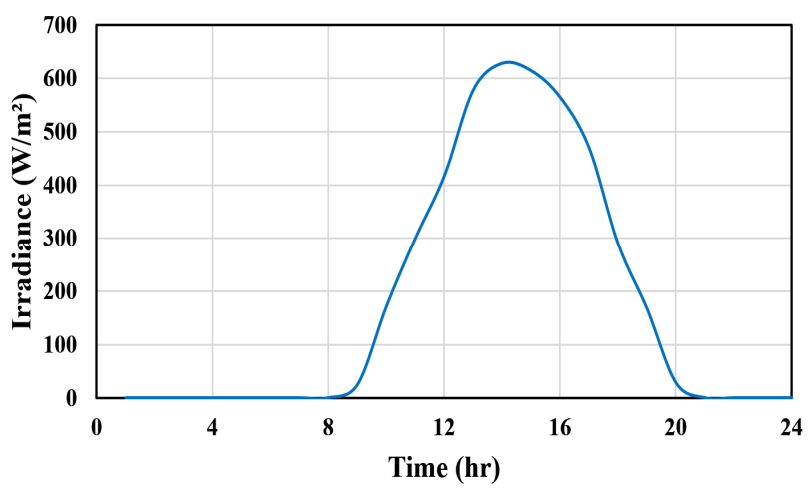

Fig. 3. Cherbourg daily solar radiation.

Table I. - Photovoltaic array characteristics.

\begin{tabular}{|c|c|c|}
\hline PARAMETER & SYMBOL & VALUE \\
\hline Rated power & $P_{r-P V}$ & $500(\mathrm{~kW})$ \\
\hline Capital Cost & $C C$ & $2000(\$ / \mathrm{kW})$ \\
\hline Replacement Cost & $R C$ & $2000(\$ / \mathrm{kW})$ \\
\hline $\begin{array}{c}\text { Operation \& Maintenance } \\
\text { Cost }\end{array}$ & $M C$ & $10(\$ / \mathrm{kW})$ \\
\hline Lifetime & $L F$ & 20 \\
\hline \multicolumn{2}{|c}{}
\end{tabular}

\section{B. Tidal}

Tidal energy can be defined as the energy extracted from tides and converted into electricity. Although it is still in its infancy, it is considered among the most predictable renewable energy sources, to within $98 \%$ accuracy [21]. The output power of tidal turbines is governed by (3).

$P_{t t}=\left\{\begin{array}{l}0, \quad v_{\text {tide }}<v_{\text {cut-in }}, v_{\text {tide }}>v_{\text {cut }- \text { out }} \\ N_{t t} 0,5 \rho A C_{p} v_{\text {tide }}^{3}, v_{\text {cut-in }}<v_{\text {tide }}<v_{r} \\ N_{t t} P_{r-t t}, \quad v_{r}<v_{\text {tide }}<v_{\text {cut }- \text { out }}\end{array}\right.$ 
Where $v_{\text {tide }}, v_{\text {cut-in }}, v_{\text {cut-out }}$ and $v_{r}$ represent the marine current velocity, the cut-in speed, the cut-out speed, and the rated speed, in $\mathrm{m} / \mathrm{s}$, respectively. $N_{t t}, P_{r-t t}, \rho, A$ and $C_{p}$ are the number of tidal turbines, the rated power $(\mathrm{kW})$, the seawater density $(1027 \mathrm{~kg} / \mathrm{m} 3)$, the turbine blades swept area $\left(\pi R^{2}\right)$ and the power coefficient, respectively. In this study, $C_{p}$ is 0,45 , which falls within its defined range of $0,35-0,5$ [15], [22]. The marine current speed profile in the Alderney Race is shown in Fig. 4. Table II presents the tidal turbine characteristics.

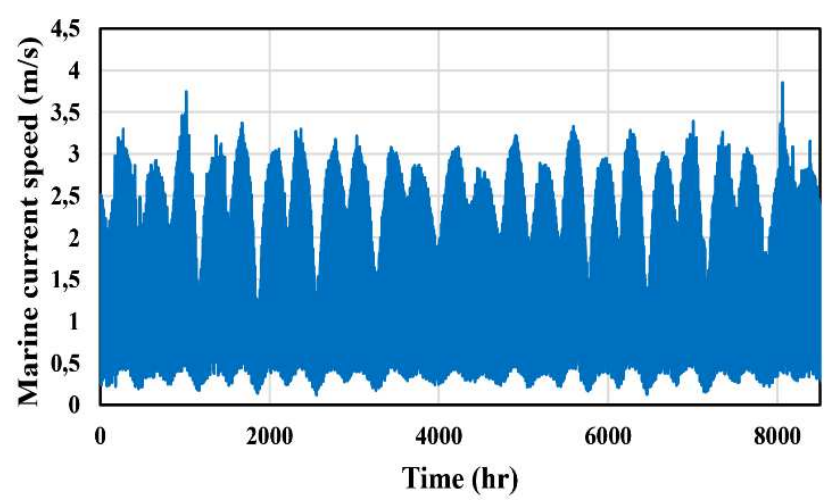

Fig. 4. Marine current speed profile for one year.

Table II. - Tidal turbine characteristics.

\begin{tabular}{|c|c|c|}
\hline PARAMETER & SYMBOL & VALUE \\
\hline Rated power & $P_{r-t t}$ & $1500(\mathrm{~kW})$ \\
\hline Rated speed & $v_{r}$ & $3,2(\mathrm{~m} / \mathrm{s})$ \\
\hline Cut-in speed & $v_{\text {cut-in }}$ & $1(\mathrm{~m} / \mathrm{s})$ \\
\hline Cut-out speed & $v_{\text {cut-out }}$ & $3,8(\mathrm{~m} / \mathrm{s})$ \\
\hline Radius & $R$ & $8(\mathrm{~m})$ \\
\hline Capital Cost & $C C$ & $5000(\$ / \mathrm{kW})$ \\
\hline Replacement Cost & $R C$ & -- \\
\hline $\begin{array}{c}\text { Operation \& Maintenance } \\
\text { Cost }\end{array}$ & $M C$ & $150(\$ / \mathrm{kW})$ \\
\hline Lifetime & $L F$ & 20 \\
\hline
\end{tabular}

\section{Battery}

When the power generated by renewable systems is not sufficient to meet the demand for electricity, the battery is selected to make up the shortfall. The energy stored in the battery $\boldsymbol{E}_{\boldsymbol{b}}$ can be calculated by (4) and (5) [23].

- During battery charging:

$E_{b}(t)=E_{\text {bat }}(t-1)(1-\sigma)+\left[E_{g}(t)-\frac{E_{L}(t)}{\eta_{\text {inv }}}\right] \cdot \eta_{b}^{c h}$

- During battery discharging:

$E_{b}(t)=E_{b a t}(t-1)(1-\sigma)-\left[\frac{E_{L}(t)}{\eta_{\text {inv }}}-E_{g}(t)\right] / \eta_{b}^{d c h}$

Where $\sigma, E_{L}, \eta_{i n v}, \eta_{b}^{c h}$ and $\eta_{b}^{d c h}$ are the hourly rate of battery self-discharge, the energy required by the load, the inverter efficiency, the battery charging efficiency and the battery discharging efficiency, respectively. $E_{g}$ represents the energy produced by the renewables, it is given by (6).

$$
E_{g}(t)=E_{p v}(t)+E_{t t}(t)
$$

In this paper, the parameters of the considered $\mathrm{LiFePO}_{4}$ battery are given in Table III.

Table III. - Battery characteristics.

\begin{tabular}{|c|c|c|}
\hline PARAMETER & SYMBOL & VALUE \\
\hline Rated energy & $E_{r-b}$ & $250(\mathrm{kWh})$ \\
\hline Charging efficiency & $\eta_{b}^{c h}$ & 0,8 \\
\hline Discharging efficiency & $\eta_{b}^{d c h}$ & 0,8 \\
\hline Depth of Discharge & $D O D$ & 0,8 \\
\hline Capital Cost & $C C$ & $343(\$ / \mathrm{kWh})$ \\
\hline Replacement Cost & $R C$ & $343(\$ / \mathrm{kWh})$ \\
\hline $\begin{array}{c}\text { Operation \& Maintenance } \\
\text { Cost }\end{array}$ & $M C$ & 0 \\
\hline Lifetime & $L F$ & 5 \\
\hline
\end{tabular}

\section{Hydrogen storage system}

Hydrogen is environmentally friendly because neither its production nor its storage or transport emit noxious gases [24]. In order to have a highly reliable and economical system, our system uses both battery and hydrogen storage. Batteries are used for fast energy storage while the hydrogen system is used for long-term energy storage. When the battery is fully charged, the excess energy generated can be stored in tanks in the hydrogen form. To this end, the electrical energy produced will be fed to an electrolyzer responsible for the separation of water to generate hydrogen at the cathode and oxygen at the anode, under the electric current effect. The hydrogen chemical energy will be converted into electrical energy by the fuel cell when there is an energy deficit. The Fuel cell, electrolyzer, and tank characteristics are presented in Table IV.

Table IV. - Hydrogen system characteristics.

\begin{tabular}{|c|c|c|c|}
\hline Component & FC & Electrolyzer & Tank \\
\hline Rated power & $1500(\mathrm{~kW})$ & $1500(\mathrm{~kW})$ & $10(\mathrm{~kg})$ \\
\hline Efficiency & $\eta_{f c}=0,7$ & $\eta_{e l z}=0,9$ & $\eta_{h}=0,8$ \\
\hline Lifetime & 5 & 20 & 20 \\
\hline $\begin{array}{c}\text { Capital Cost } \\
(\mathrm{CC})\end{array}$ & $\begin{array}{c}3000 \\
(\$ / \mathrm{kW})\end{array}$ & $\begin{array}{c}2000 \\
(\$ / \mathrm{kW})\end{array}$ & $\begin{array}{c}660 \\
(\$ / \mathrm{kg})\end{array}$ \\
\hline $\begin{array}{c}\text { Replacement } \\
\text { Cost }\end{array}$ & 2500 & 1500 & 400 \\
\hline O\&M Cost & $0,02 * \mathrm{CC}$ & $0,01 * \mathrm{CC}$ & $0,02 * \mathrm{CC}$ \\
\hline
\end{tabular}

The power of the electrolyzer and the fuel cell are given by (7) and (8), respectively.

$$
\begin{gathered}
P_{e L z}=N_{e l z} \cdot I_{e l z} \cdot V_{e l z} \\
P_{f c}=N_{f c} \cdot I_{f c} \cdot V_{f c}
\end{gathered}
$$


Where $N_{e L z}, I_{e L z}, V_{e L z}$ are the number of electrolyzers, the electrolyzer current (A) and its voltage (V), respectively. $N_{f c}, I_{f c}, V_{f c}$ are the number of fuel cells, the fuel cell output current (A) and its output voltage (V), respectively.

\section{Optimization Strategy}

In this section, the system optimal sizing is presented, in order to determine the best configuration (Number of tidal turbines, photovoltaic arrays, batteries, fuel cells, electrolyzers, and tanks), from an economic and energetic point of view.

\section{A. Proposed objective function}

The objective function is to minimize the hybrid system cost by respecting certain reliability indices. The ones we used are the loss of power supply probability (LPSP) and the equivalent loss factor (ELF).

In this paper, the net present cost (NPC) is considered, which includes the capital cost (CC), replacement cost (RC) and maintenance cost (MC) of each component. The objective function is defined as in (9) [15].

$$
N P C=\sum_{j=1}^{L} N_{j} \cdot P_{j}\left(C C_{j}+R C_{j} . K_{j}+M C_{j} \cdot P W A\left(i_{r}, R\right)\right.
$$

Where $\mathrm{L}$ is the number of components in the hybrid system (L=6), $N_{j}$ is the optimization algorithm decision variable that stands for the number of each component $\left(N_{t t}, N_{p v}, N_{b}, N_{e l z}, N_{f c}, N_{h}\right) . N_{t t}, N_{e l z}, N_{f c}$ are, respectively, the number of tidal turbines, electrolyzers and fuel cells with 1,5 MW rated power. $N_{p v}$ is the number of PV arrays with $500 \mathrm{~kW}$ rated power, $N_{b}$ is the number of batteries with $250 \mathrm{kWh}$ rated energy and $N_{h}$ is the number of $10 \mathrm{~kg}$ tanks. $P_{j}$ is the rated power of each component. In order to convert the replacement cost of a component at the end of its lifetime to present cost, $\mathrm{K}_{\mathrm{j}}$ is used; it can be calculated by (10) [25].

$$
K_{j}=\sum_{n=1}^{l_{1}} \frac{1}{\left(1+i_{r}\right)^{n * l_{2}}}
$$

Where $l_{1}$ represents the replacement frequency of a renewable source, $l_{2}$ is its lifetime and $i_{r}$ is the interest rate $\left(i_{r}=0,06\right)$. It is worth noting that for sources with a lifetime equal to the project lifetime, $K_{j}$ is equal to zero. $P W A\left(i_{r}, R\right)$ is used to estimate the present value of maintenance and operation annual cost over the project lifetime, it is given by (11) [25].

$$
P W A(i r, R)=\frac{\left(1+i_{r}\right)^{R}-1}{i_{r}\left(1+i_{r}\right)^{R}}
$$

Where, $\mathrm{R}$ is the total lifetime of the project, which is 20 years.

\section{B. Reliability indices}

In this paper, LPSP and ELF have been selected as reliability indices. These indices allow us to determine the configuration that ensures a reliable power supply at the lowest cost. LPSP is a statistical parameter that indicates the probability of power supply loss either due to the renewable resource unavailability or to a technical failure [5]. LPSP and ELF can be calculated by (12) and (13), respectively.

$$
\begin{aligned}
& L P S P=\frac{\sum_{t=1}^{T} E_{\text {unmet }}(t)}{\sum_{t=1}^{T} E_{L}(t)} \\
& E L F=\frac{1}{T} \sum_{t=1}^{T} \frac{P_{\text {unmet }}(t)}{P_{L}(t)}
\end{aligned}
$$

Where $\mathrm{T}$ represents the period during which the data were used, i.e. 8760 h. $E_{\text {unmet }}$ represents the unmet load, it can be expressed by (14).

$$
\begin{aligned}
& E_{\text {unmet }}(t)=E_{L}-\left(E_{g}(t)+E_{f c}(t)+\left(E_{b}(t)-\right.\right. \\
& \left.\left.E_{\text {bmin }}\right)\right)
\end{aligned}
$$

\section{Constraints}

In order to size the system correctly, the following constraints are defined:

$$
\begin{gathered}
1 \leq N_{t t} \leq N_{t t \max } \\
1 \leq N_{p v} \leq N_{\text {pvmax }} \\
1 \leq N_{b} \leq N_{b \max } \\
1 \leq N_{\text {elz }} \leq N_{\text {elzmax }} \\
1 \leq N_{f c} \leq N_{f c \max } \\
1 \leq N_{h} \leq N_{\text {hmax }} \\
E L F \leq E L F_{\max } \\
L P S P \leq L P S P_{\max }
\end{gathered}
$$

\section{Optimization algorithms}

An optimal sizing program was developed in Matlab software using metaheuristic optimization methods. These methods are particle swarm optimization (PSO) and genetic algorithm (GA).

PSO is a method derived from stochastic descent, developed in 1995 by Kennedy and Eberhart. It is based on the behavior of birds to compute global optimization functions. Each partner in the swarm is called a particle. These particles are randomly placed in the search space of the objective function to be minimized. Each particle is characterized by its position $\overrightarrow{\boldsymbol{x}}$ and velocity $\overrightarrow{\boldsymbol{v}}$. At each iteration, these particles move towards their best position and therefore that of their neighborhood, which corresponds to the optimum position, by updating their 
velocity [15], [26]. Fig. 5 illustrates the flowchart of the proposed algorithm PSO in detail.

GA is a search heuristic that is inspired by Charles Darwin's theory of natural evolution. The main operators of GA are the "selection", the "crossover" and the "mutation". These operators have an important role in the success of the optimization because they influence the evolution from the initial population to the final population. At each iteration, the best individuals are selected for reproduction, while maintaining a certain diversity to avoid premature convergence towards a local minimum [27].

The parameters of the PSO algorithm and those of GA considered in this study are shown in Table V.

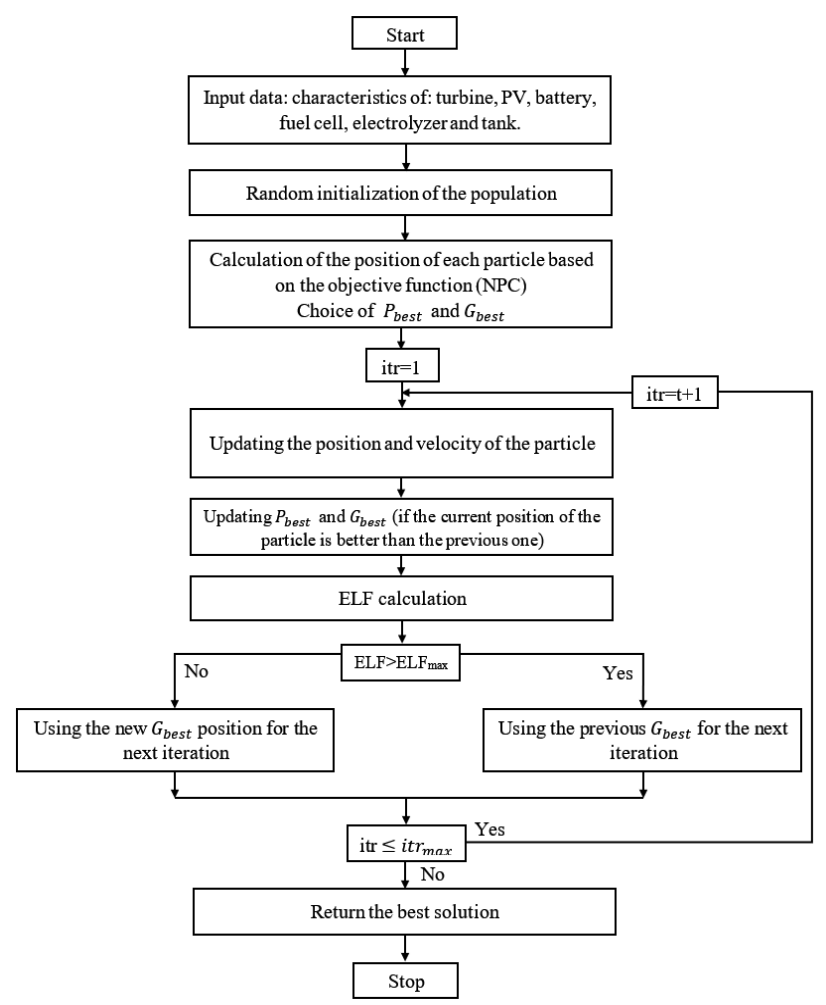

Fig. 5. Particle Swarm Optimization flowchart.

Table V. - GA and PSO Parameters.

\begin{tabular}{|c|c|c|}
\hline & QUANTITY & VALUE \\
\hline \multirow{6}{*}{ 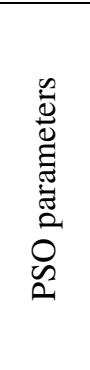 } & Swarm size & 50 \\
\hline & Max. number of iterations & 100 \\
\hline & $\begin{array}{c}\text { Personal acceleration } \\
\text { coefficient }\end{array}$ & 2 \\
\hline & $\begin{array}{c}\text { Social acceleration } \\
\text { coefficient }\end{array}$ & 2 \\
\hline & Inertia coefficient & 1 \\
\hline & $\begin{array}{l}\text { Inertia coefficient damping } \\
\text { ratio }\end{array}$ & 0,99 \\
\hline \multirow{6}{*}{ 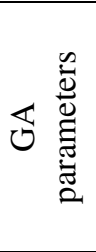 } & Number of variables & 23 \\
\hline & Population size & 100 \\
\hline & Max. number of iterations & 200 \\
\hline & Crossover percentage & 0,8 \\
\hline & Mutation rate & 0,02 \\
\hline & Number of mutants & random \\
\hline
\end{tabular}

\section{Simulation Results}

The optimal sizing was applied to meet the energy consumption of the residential loads. To address the problem of intermittent renewable energies, an energy management strategy is adopted. This strategy considers the availability of green energy and the load demand at all times. The optimization algorithms are intended to select the best configuration, considering the aforementioned constraints. In order to find the optimal solution to achieve the minimum cost, we ran the simulations several times based on one year's data. Table VI presents the results obtained by the two optimization methods with the minimum installation cost NPC (net present cost).

Table VI. - The Optimization Results.

\begin{tabular}{|c|c|c|}
\hline OPTIMIZATION METHOD & PSO & GA \\
\hline$N_{t t}$ & 1 & 1 \\
\hline$N_{p v}$ & 6 & 6 \\
\hline$N_{b}$ & 1 & 2 \\
\hline$N_{e l z}$ & 1 & 1 \\
\hline$N_{f c}$ & 1 & 1 \\
\hline$N_{h}$ & 109 & 96 \\
\hline$N P C(\$)$ & $3,288 \mathrm{e}+07$ & $3,30 \mathrm{e}+07$ \\
\hline$E L F$ & 0,0137 & 0,0142 \\
\hline$L P S P$ & 0,01 & 0,023 \\
\hline
\end{tabular}

Convergence was achieved at the 46th and 24th iteration for PSO and GA, respectively. The optimal cost obtained by PSO is $\$ 32,88 \mathrm{MM}$, suggesting to use 1 tidal turbine, 6 photovoltaic arrays, one battery, one electrolyzer, one fuel cell, and 109 hydrogen tanks (which represents a total capacity of $1090 \mathrm{~kg}$ at a pressure level of $30 \mathrm{bar}$ ), with an ELF equal to $1,37 \%$ and an LPSP equal to $1 \%$. The results obtained by GA are similar to those obtained by PSO, except for the number of batteries that is 2 and the number of tanks that is 96 (total capacity of $960 \mathrm{~kg}$ ). The installation cost is $\$ 33,01 \mathrm{MM}$ with an ELF equal to $1,42 \%$ and an LPSP equal to $2,3 \%$. Compared with the GA algorithm, the PSO reduces the NPC by $0,4 \%$, which is not enormous. The results are consistent and almost similar, this allows us to validate the energy management we have developed on Matlab as well as the two optimization algorithms.

To better visualize the proposed optimal system, Fig. 6 illustrates the energy generated by the hybrid system and the energy consumed by the load during one week (168h). From this graph, we can see that the batteries and fuel cells cover the periods when the energy generated is not sufficient to supply the load, especially at night since there is no photovoltaic energy. Similarly, the batteries are charged and the electrolyzer produces hydrogen when the power generated is greater than that required. The electrolyzer and fuel cell do not operate simultaneously, avoiding the use of a hydrogen production system as an electrical storage system. The amount of hydrogen never goes below $218 \mathrm{~kg}$ (minimum allowed quantity), which 
means that the constraints imposed on the hydrogen system are satisfied, as shown in Fig. 7. Fig. 8 presents the contribution of each technology to the system's total cost. We can clearly notice that the fuel cell has the major share in the total cost, up to $36,5 \%$, due to its high capital cost and replacement cost, which is why only one fuel cell is proposed, followed by the tidal turbine, the PV arrays, the electrolyzer, the tanks and the battery. Thus, a significant reduction in the cost of fuel cells and tidal turbines can lead to further savings. Batteries and hydrogen tanks have a relatively low cost, hence their minor contribution to the NPC compared to the other components. It should be noted that there is no replacement cost for tidal turbines, PV arrays, electrolyzers, and hydrogen tanks since their life span is equal to the system life span (20 years).

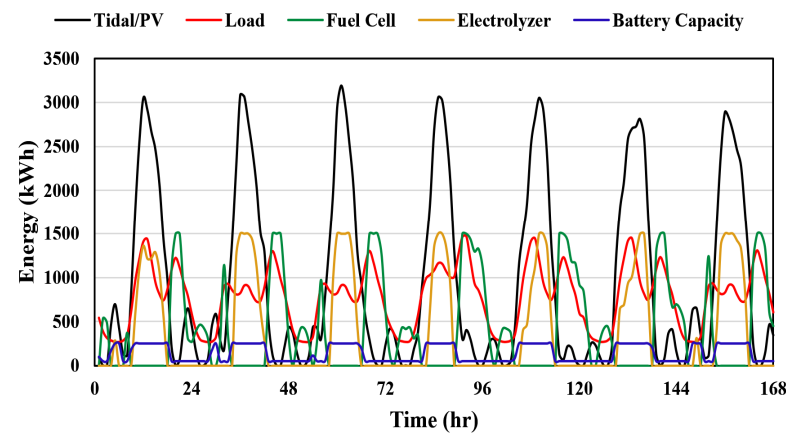

Fig. 6. Generated energy from the hybrid system and required energy for one week.

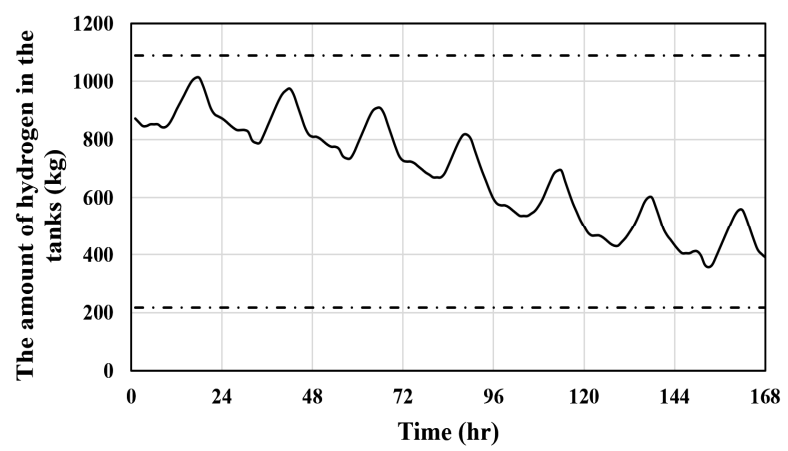

Fig. 7. Amount of hydrogen in the hydrogen tanks.

Net Present Cost (NPC) Distribution

- PV $\mid$ Tidal $=$ Battery $=$ Electrolyzer $=$ Fuel cell $=$ Tank

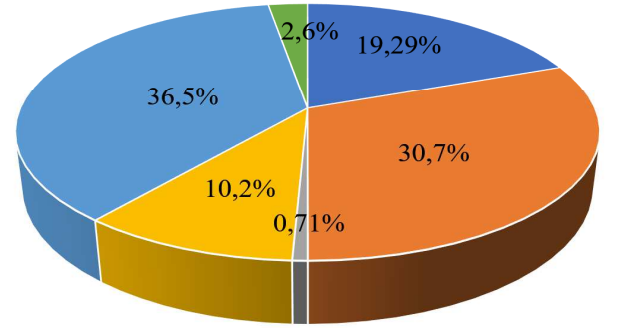

Fig. 8. Contribution of each component in the NPC.

\section{Conclusion}

In this paper, the optimal sizing of a new hybrid renewable energy system is presented, using two algorithms called PSO and GA. In order to address renewable sources' intermittency, an energy management strategy has been implemented to balance energy between production and consumption. Net present cost (NPC) has been selected as an objective function, considering LPSP and ELF as reliability indices. The results showed that PSO is better compared to GA, in terms of cost savings and reliability, with an NPC of $\$ 32,88 \mathrm{MM}$.

The proposed method can be applied to a wide variety of problems; it offers a compromise between the solution quality and the calculation time of the optimization problem. It can be used as a support tool to optimize the sizing of the power supply system for various loads such as data centers oriented towards solutions aimed at autonomy, economy, and ecology.

\section{Acknowledgement}

This work was supported by contracts and projects of LUSAC Laboratory, who funded the Ph.D. thesis of the first author.

\section{References}

[1] Y. Sawle and S. C. Gupta, "Optimal sizing of photovoltaic/wind hybrid energy system for rural electrification," in 2014 6th IEEE Power India International Conference (PIICON), Delhi, Dec. 2014, pp. $1-4$.

[2] G. Sandeep and V. S. Vakula, "Optimal combination and sizing of a standalone hybrid power system using HOMER," in 2016 International Conference on Electrical, Electronics, and Optimization Techniques (ICEEOT), Chennai, India, 2016, pp. 4141-4144.

[3] H. Belmili, M. Haddadi, S. Bacha, M. F. Almi, and B. Bendib, "Sizing stand-alone photovoltaic-wind hybrid system: Techno-economic analysis and optimization," Renewable and Sustainable Energy Reviews, vol. 30, pp. 821-832, Feb. 2014.

[4] O. Erdinc and M. Uzunoglu, "Optimum design of hybrid renewable energy systems: Overview of different approaches," Renewable and Sustainable Energy Reviews, vol. 16, no. 3, pp. 1412-1425, Apr. 2012.

[5] H. Borhanazad, S. Mekhilef, V. Gounder Ganapathy, M. Modiri-Delshad, and A. Mirtaheri, "Optimization of micro-grid system using MOPSO," Renewable Energy, vol. 71, pp. 295-306, Nov. 2014.

[6] S. M. Hakimi, S. M. M. Tafreshi, and A. Kashefi, "Unit Sizing of a Stand-alone Hybrid Power System Using Particle Swarm Optimization (PSO)," in 2007 IEEE International Conference on Automation and Logistics, Jinan, China, 2007, pp. 3107-3112.

[7] M. Kandil, M. Saadawi, M. Saeed, and A. Hassan, "Modified particle swarm optimisation technique for optimal design of small renewable energy system supplying a specific load at Mansoura University," IET Renewable Power Generation, vol. 9, no. 5, pp. 474-483, Jul. 2015.

[8] D. Feroldi and D. Zumoffen, "Sizing methodology for hybrid systems based on multiple renewable power sources integrated to the energy management strategy," International Journal of Hydrogen Energy, vol. 39, no. 16, pp. 8609-8620, May 2014.

[9] A. Mahesh and K. S. Sandhu, "Optimal sizing of a $\mathrm{PV} /$ Wind hybrid system using pigeon inspired 
optimization," in 2016 IEEE 7th Power India International Conference (PIICON), Bikaner, Rajasthan, India, 2016, pp. 1-6.

[10] K. M. Sba, Y. Bakelli, A. Kaabeche, and S. Khenfous, "Sizing Of A Hybrid (Photovoltaic/Wind) Pumping Systembased On Metaheuristic Optimization Methods," in 2018 International Conference on Wind Energy and Applications in Algeria (ICWEAA), Algiers, 2018, pp. 16.

[11] H. Bakhtiari and R. A. Naghizadeh, "Multi-criteria optimal sizing of hybrid renewable energy systems including wind, photovoltaic, battery, and hydrogen storage with $\varepsilon$ constraint method," IET Renewable Power Generation, vol. 12, no. 8, pp. 883-892, Jun. 2018.

[12] W. Dong, Y. Li, and J. Xiang, "Sizing of a stand-alone photovoltaic/wind energy system with hydrogen and battery storage based on improved ant colony algorithm," in 2016 Chinese Control and Decision Conference (CCDC), Yinchuan, China, 2016, pp. 4461-4466.

[13] M. J. Hadidian Moghaddam, A. Kalam, S. A. Nowdeh, A. Ahmadi, M. Babanezhad, and S. Saha, "Optimal sizing and energy management of stand-alone hybrid photovoltaic / wind system based on hydrogen storage considering LOEE and LOLE reliability indices using flower pollination algorithm," Renewable Energy, vol. 135, pp. 1412-1434, May 2019.

[14] M. Jamshidi and A. Askarzadeh, "Techno-economic analysis and size optimization of an off-grid hybrid photovoltaic, fuel cell and diesel generator system," Sustainable Cities and Society, vol. 44, pp. 310-320, Jan. 2019.

[15] M. Bashir and J. Sadeh, "Size optimization of new hybrid stand-alone renewable energy system considering a reliability index," in 2012 11th International Conference on Environment and Electrical Engineering, Venice, Italy, 2012, pp. 989-994.

[16] "Le solaire photovoltaïque en chiffres," EDF France, 20Jul-2015. [Online]. Available: https://www.edf.fr/groupeedf/espaces-dedies/l-energie-de-a-a-z/tout-sur-lenergie/pr oduire-de-1-electricite/le-solaire-photovoltaique-en-chiffre s. [Accessed: 24-Dec-2019].

[17] O. A. L. Brutto, M. R. Barakat, S. S. Guillou, J. Thiebot, and H. Gualous, "Influence of the Wake Effect on Electrical Dynamics of Commercial Tidal Farms: Application to the Alderney Race (France)," IEEE Trans. Sustain. Energy, vol. 9, no. 1, pp. 321-332, Jan. 2018.

[18] M. Barakat, "Development of models for integrating renewables and energy storage components in smart grid applications," Ph.D. dissertation, Dept. Elect. Eng., Caen Normandy Univ., Cherbourg, France, 2018.

[19] M. Kharrich, M. Akherraz, and Y. Sayouti, "Optimal sizing and cost of a Microgrid based in PV, WIND and BESS for a School of Engineering," in 2017 International Conference on Wireless Technologies, Embedded and Intelligent Systems (WITS), Fez, Morocco, 2017, pp. 1-5.

[20] A. M. Abdelshafy, H. Hassan, and J. Jurasz, "Optimal design of a grid-connected desalination plant powered by renewable energy resources using a hybrid PSO-GWO approach," Energy Conversion and Management, vol. 173, pp. 331-347, Oct. 2018.

[21] M. R. Barakat, B. Tala-Ighil, H. Chaoui, H. Gualous, Y. Slamani, and D. Hissel, "Energetic Macroscopic Representation of a Marine Current Turbine System with Loss Minimization Control," IEEE Trans. Sustain. Energy, vol. 9, no. 1, pp. 106-117, Jan. 2018.

[22] S. E. Ben Elghali, M. E. H. Benbouzid, and J.-F. Charpentier, "Modelling and control of a marine current turbine-driven doubly fed induction generator," IET Renew. Power Gener., vol. 4, no. 1, p. 1, 2010.
[23] A. Khiareddine, C. Ben Salah, D. Rekioua, and M. F. Mimouni, "Sizing methodology for hybrid photovoltaic /wind/ hydrogen/battery integrated to energy management strategy for pumping system," Energy, vol. 153, pp. 743762, Jun. 2018.

[24] A. Tabanjat, M. Becherif, D. Hissel, and H. S. Ramadan, "Energy management hypothesis for hybrid power system of $\mathrm{H} 2$ /WT/PV/GMT via AI techniques," International Journal of Hydrogen Energy, vol. 43, no. 6, pp. 35273541, Feb. 2018.

[25] N. Lazaar, E. Fakhri, M. Barakat, J. Sabor, and H. Gualous, "A Genetic Algorithm Based Optimal Sizing Strategy for PV/Battery/Hydrogen Hybrid System," in Artificial Intelligence and Industrial Applications, vol. 144, T. Masrour, I. El Hassani, and A. Cherrafi, Eds. Cham: Springer International Publishing, 2021, pp. 247-259.

[26] H. Awad, K. M. E. Salim, and M. Gül, "Multi-objective design of grid-tied solar photovoltaics for commercial flat rooftops using particle swarm optimization algorithm," Journal of Building Engineering, vol. 28, p. 101080, Mar. 2020.

[27] J. Grefenstette, "Optimization of Control Parameters for Genetic Algorithms," IEEE Trans. Syst., Man, Cybern., vol. 16, no. 1, pp. 122-128, Jan. 1986. 